\title{
REZENSIONEN
}

\section{Einführung in den Parlamentarismus: nicht mehr und nicht weniger}

Marschall, Stefan: Parlamentarismus. Eine Einführung, Nomos Verlagsgesellschaft, BadenBaden 2005, 350 Seiten, $€ 21,90$.

Es ist eine Unart, dass heutzutage manche Studie nicht zuletzt aus verkaufsstrategischen Gründen als „Einführung“ firmiert, obwohl davon keine Rede sein kann. In diesem Fall handelt es sich um keinen Etikettenschwindel. Die Arbeit von Stefan Marschall über den „Parlamentarismus“, wobei ein weitgefasstes Parlamentarismusverständnis zugrunde gelegt wird, also auch Präsidialdemokratien darunter fallen, hält das, was der Untertitel verspricht. Der von dem Passauer Politikwissenschaftler Winand Gellner herausgegebene „Studienkurs Politikwissenschaft" will angesichts neuer Studiengänge dem Sachverhalt Rechnung tragen, dass „in sehr kurzer Zeit hochgradig standardisierter politikwissenschaftlicher Stoff vermittelt werden muss, der in das sich immer stärker durchsetzende Klausurformat passt“ (S. 5). Der in dieser Reihe publizierte Band Marschalls trägt diesem Anliegen Rechnung. Am Ende jedes der sechs Kapitel finden sich: Zusammenfassung, Auswahlliteratur, Links sowie Wiederholungsfragen. Außerdem enthält der Band 18 Tabellen und vier Abbildungen, ferner einige (wenige) Quellentexte. Personen- und Sachregister hätten die Benutzbarkeit weiter gesteigert. Die vielen „Regieanweisungen“ haben eine didaktische Funktion, stören aber ein wenig den Lesefluss.

Stefan Marschall, der mit der Materie bestens vertraut ist ${ }^{1}$, gliedert seinen Text in sechs Kapitel, die von einer knappen Einleitung („Parlamentarismus - ein Erfolgsmodell ohne Zukunft?") und einem Schlussabschnitt („Kein Ende des Parlamentarismus“) eingerahmt sind: Grundlagen, Struktur und Organisation von Parlamenten, Parlamentsfunktionen, Parlamentarismus unterhalb und oberhalb des Nationalstaates, Parlamentarismuskritik, Neoparlamentarische Perspektiven. Diese Gliederung ist sinnvoll, und schlüssig werden die einschlägigen Themen abgehandelt. Allerdings gibt es eine Reihe von Überschneidungen zwischen Kapitel IV.2. „Transnationaler Parlamentarismus“ (über das Europäische Parlament und Parlamentarische Versammlungen) und Kapitel VI.3. „,Parlamentarische Demokratie' jenseits des Nationalstaates" (unter anderem über das Europäische Parlament und Parlamentarische Versammlungen).

Das Lehrbuch besticht durch common sense. Die offensive Verteidigung des Parlamentarismus und das Plädoyer für Reformbewusstsein muten sympathisch an. Wer etwa Informationen über die begrifflichen Wurzeln sucht, über den Bikameralismus, die Funktionska-

1 Vgl. Stefan Marschall, Parlamentsreform. Ziele - Akteure - Prozesse, Opladen 1999; ders., Öffentlichkeit und Volksvertretung. Theorie und Praxis der Public Relations von Parlamenten, Opladen 1999; ders., Transnationale Repräsentation in parlamentarischen Versammlungen. Demokratie und Parlamentarismus jenseits des Nationalstaates, Baden-Baden 2005. 
taloge von Parlamenten oder über die Parlamente in Transformationsstaaten, um ein paar Beispiele herauszugreifen, ist mit dem Band gut bedient. Die Fallbeispiele, derer sich der Autor zur Illustrierung seiner Argumentation bedient, sind - natürlich - das britische Unterhaus, auch der Deutsche Bundestag und der US-Kongress sowie die französische Nationalversammlung und das Europäische Parlament. Die heikle Frage nach der Existenz semipräsidentieller Systeme wird zwar erörtert, aber nicht klar beantwortet. Die Position des Autors erfährt der Leser nicht. Das Kapitel über „Parlamentarismuskritik“ mit Ausführungen zu Carl Schmitt und Johannes Agnoli ${ }^{2}$ hätte ebenso eine Vertiefung verdient wie der Abschnitt über „,Parlamentarismus' in nicht-demokratischen Systemen“. Ausführungen zu den Herausforderungen des Parlamentarismus (zum Beispiel Globalisierung und Entwicklung hin zu einer „Mediendemokratie“) kommen etwas zu kurz.

„Mir geht es nicht nur darum, Erkenntnisse der Parlamentarismusforschung für Interessierte zusammenzustellen und verdaubar zu machen. Darüber hinaus sollen Fragen leitend sein, die Anschlusspunkte für weitere Auseinandersetzung bieten: Wie hat sich der Parlamentarismus gewandelt? Welche Veränderungen stehen ihm noch bevor? Hat Parlamentarismus eine Zukunft und - wenn ja - welche?" (S. 18) Diesen Anspruch, der in den Fragen aufscheint, löst der Verfasser nicht ganz ein. Dies ist auch keineswegs die Aufgabe einer derartigen Einführung in den Parlamentarismus. Um eine solche handelt es sich - nicht mehr und nicht weniger.

Eckhard Jesse

2 Vgl. weiterführend Wolfgang Kraushaar, Agnoli, die APO und der konstitutive Illiberalismus seiner Parlamentarismuskritik, in: ZParl, 38. Jg. (2007), H. 1, S. 160 - 179; siehe dazu auch Uwe Thaysen / Jürgen W. Falter, Fraenkel versus Agnoli? Oder: Was ist aus der „Parlamentsverdrossenheit“ der 60er Jahre für die heutige „Postparlamentarismus“-Diskussion zu lernen?, in: ZParl, 38. Jg. (2007), H. 2, S. $401-413$.

\section{Frankreich: das politische System im aktuellen Überblick}

Kempf, Udo: Das politische System Frankreichs, 4., aktualisierte und erweiterte Auflage, VS Verlag für Sozialwissenschaften, Wiesbaden 2007, 467 Seiten, € 29,90.

Udo Kempf behandelt in der vierten Auflage dieses Buches - die vorige Auflage war 1997 unter dem Obertitel „Von de Gaulle bis Chirac“ erschienen - Verfassungsnorm und Verfassungspraxis des politischen Systems Frankreichs bis zum Ende der zwölf Jahre währenden Präsidentschaft Jacques Chiracs. 1995 ins Amt gekommen, war dieser nach der Verkürzung der Amtszeit des Präsidenten von sieben auf fünf Jahre 2002 wieder gewählt worden. Chirac verzichtete auf eine - rechtlich mögliche - abermalige Kandidatur, womit der Weg frei war für seinen von ihm nicht als Nachfolger gewünschten Innenminister Nicolas Sarkozy, dem es als Vorsitzenden der neogaullistischen Regierungspartei Union pour un Mouvement Populaire (UMP) gelungen war, die Parteibasis an sich zu binden. 